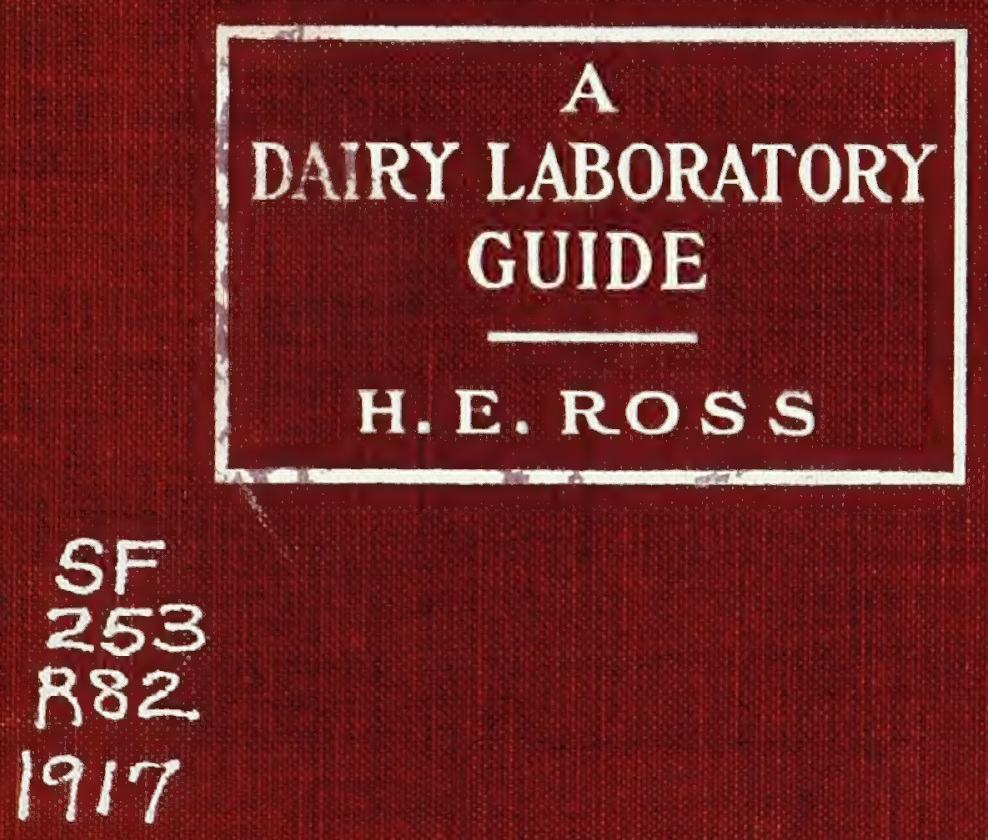




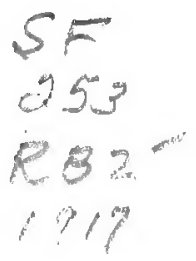

CORNELL UNIVERSITY THE

Flourer Heterinary Withrary FOUNDED BY ROSWELL P. FLOWER

for the use of the

N. Y. State Veterinary College 1897

This Volume is the Gift of

Alice I. Dustan

from the library of

Dr. Henry W. Dustan 198 
SF 253.R82 Cornell University Library

\section{A dairy laboratory guide,}

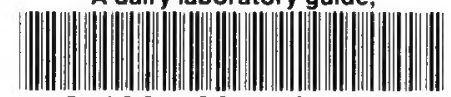

$\begin{array}{lllll}31924 & 001 & 161 & 599\end{array}$ 


\section{Cornell University Library}

The original of this book is in the Cornell University Library.

There are no known copyright restrictions in the United States on the use of the text. 



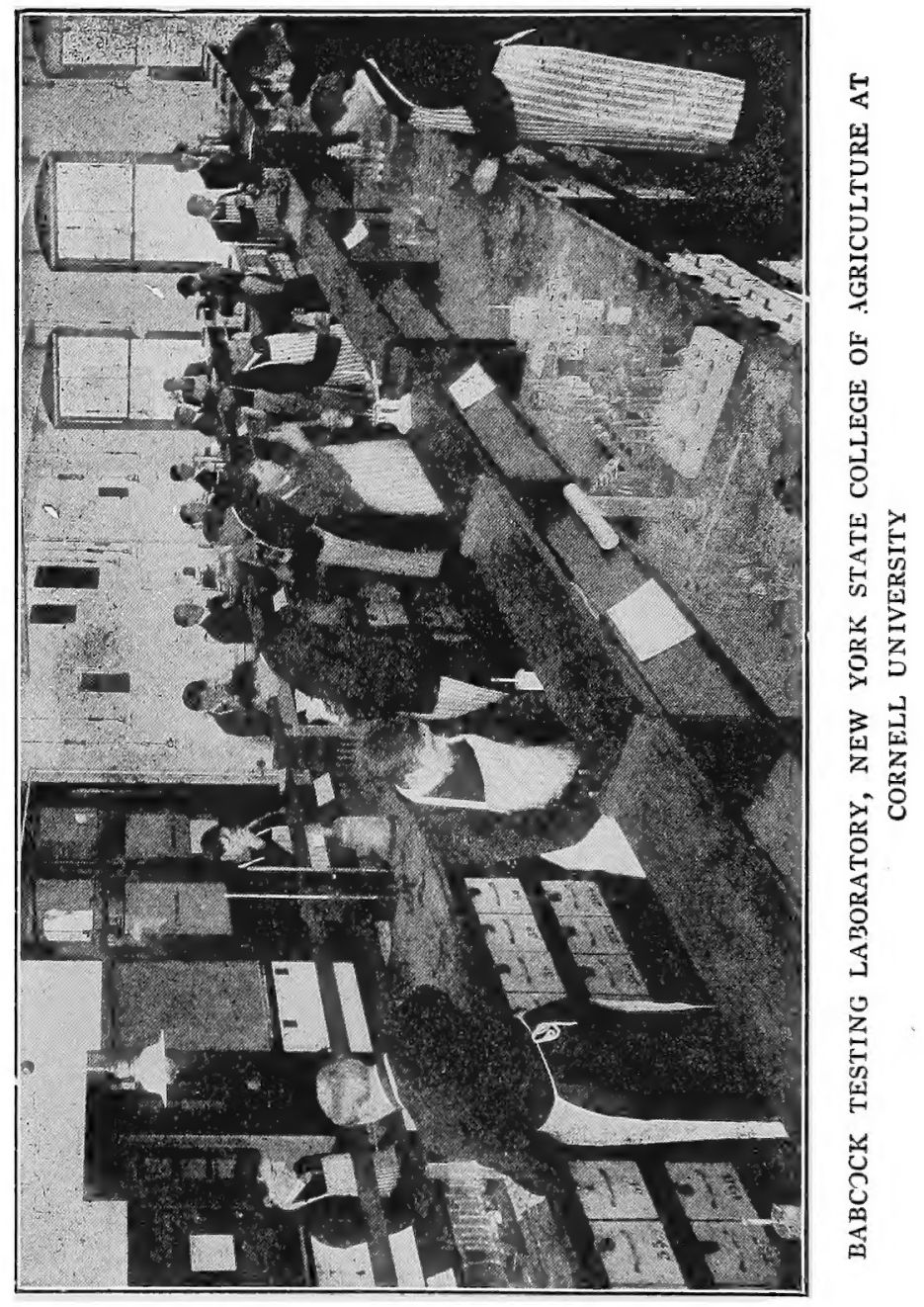




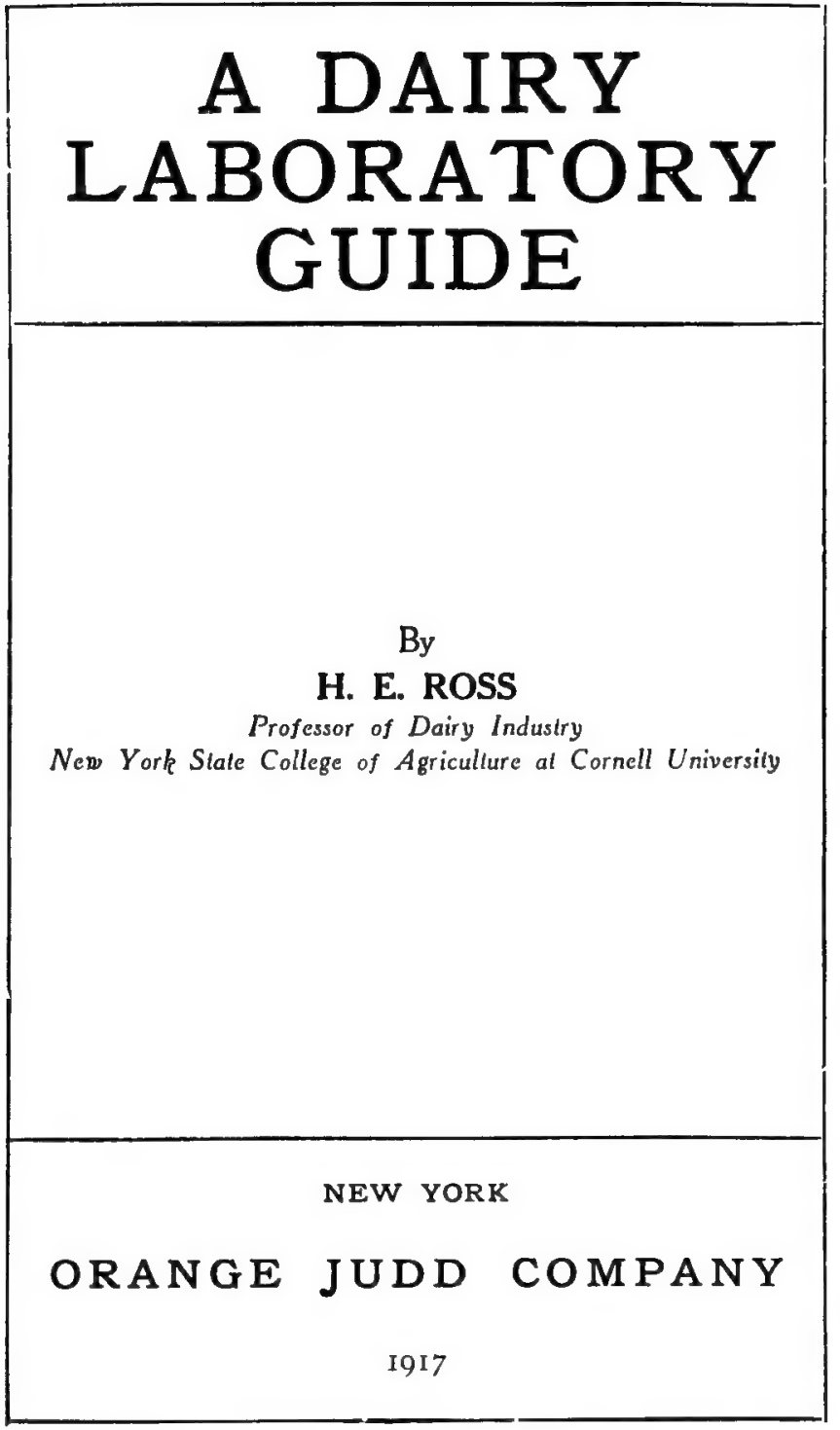


ho. 14289

Copyright, 1910-1914, by

ORANGE JUDD COMPANY

All Rights Reserved
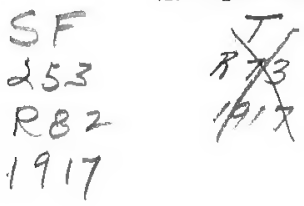


\section{PREF A C E}

In the study of any science the student should, so far as possible, work out his own problems. Yet the beginner may be saved much useless time and labor by helpful suggestions at the proper time. This Manual is designed as a guide to students in dairy laboratory work, with just enough explanation given to supplement the exercises which are outlined in the Manual. It is not intended for a text book and should not be used in the place of one.

The author's thanks are due Prof. W. A. Stocking, Jr., for many helpful suggestions in the arrangement and preparation of this book.

The author recognizes that a book of this kind needs frequent revision, and an effort will be made to keep this Manual up to date.

H. E. Ross.

Dairy Laboratories, New York State College of Agriculture, at Cornell L'niz'ersily.

August 31, 1910 



\section{TABLE OF CONTENTS}

I

The Composition of Milk.............. I

II

Explanation. The Babcock Test......... 5

III

Explanation of Poiled Milk Test and Formaldehyde Test .................. I 8

\section{IV}

Explanation. Mixing Samples of Butter Before Testing for Fat and Moisture..... I9

\section{$\mathrm{V}$}

Explanation. The C. U. liutter Moisture Test 23

\section{VI}

Explanation. The Specific Gravity of Milk and the Lactometer ................ 27

\section{VII}

Explanation. The Board of Health Lactometer 37 


\section{VIII}

Explanation. Use of the Hand Machine in Babcock Test .................. 38

IX

Explanation. The Acidity of Milk......... 43

\section{$\mathrm{X}$}

Explanation. The Effect of Speed of Machine on the Babcock Test.............. 5I

\section{$\mathrm{XI}$}

Explanation. Commercial Rennet and Its Use. 69 


\section{A Dairy Laboratory Guide}

\section{THE COMPOSITION OF MILK}

Milk is composed of a great many substances, but, so far as the dairyman is concerned, there are only six constituents which are of prime importance. The following table gives the constituents of milk, together with the per cent of each, obtained by a large number of analyses:

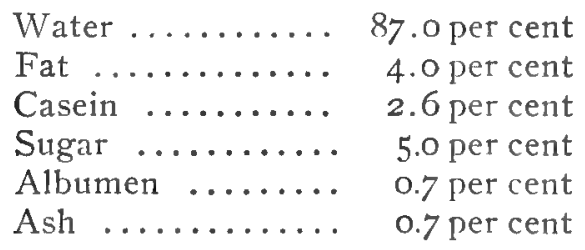

Although in the above table the different constituents are given definite per cents, yet the composition of normal milk is rery variable. The water needs no discussion, as it is just like the water found anywhere else in nature.

Fat is present in milk in the form of minute droplets or globules. These globules are distributed throughout the milk and are not in solution, but in fine suspension. This state is called an cmulsion. It was disputed for a long time as to whether or not the fat globule had a membrane around it. It is now believed by the best authorities that the fat globule his no membrane, but that the droplet 


\section{VIII}

Explanation. Use of the Hand Machine in Babcock Test ................. 38

\section{IX}

Explanation. The Acidity of Milk........ 43

$\mathrm{X}$

Explanation. The Effect of Speed of Machine on the Babcock Test.............. 5I

XI

Explanation. Commercial Rennet and Its Use. 69 


\section{A Dairy Laboratory Guide}

\section{THE COMPOSITION OF MILK}

Milk is composed of a great many substances, but, so far as the dairyman is concerned, there are only six constituents which are of prime importance. The following table gives the constituents of milk, together with the per cent of each, obtained by a large number of analyses:

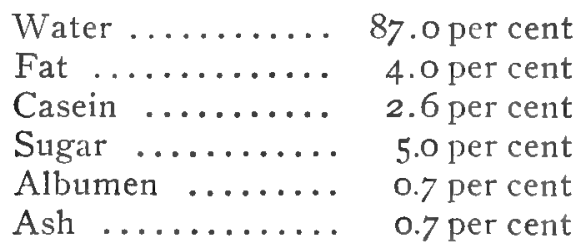

Although in the above table the different constituents are given definite per cents, yet the composition of normal milk is very variable. The water needs no discussion, as it is just like the water found anywhere else in nature.

Fat is present in milk in the form of minute droplets or globules. These globules are distributed throughout the milk and are not in solution, but in fine suspension. This state is called an cmulsion. It was disputed for a long time as to whether or not the fat globule had a membrane around it. It is now believed ly the best authorities that the fat globule has no membrane, but that the droplet 
keeps its circular form because of its power of condensing upon its surface the serum of the milk. The size of the fat globules differ in milk from different breeds of cows, and it is supposed that the larger the fat globules the more easily they rise to the surface when the milk is left standing in a vessel.

Butter is composed largely of fat, so we speak of the fat of milk as butter fat.

Fat is the most important constituent of the milk, because milk which contains a fair amount of butter fat is more valuable as a food than a milk which is poor in fat. The other food constituents of the milk usually increase or decrease as the fat increases or decreases. This is true, however, only within certain limits.

Fat is an important constituent of nearly all of the products of milk, so that in most cases a milk rich in fat is more valuable for manufacturing purposes than a milk poor in fat.

On account of the importance of the fat, it is made oftentimes a basis of payment for milk.

Butter fat is composed mainly of nine different fats. There are a few fats which are present in such minute quantities that they are of no practical importance. All of the fats have the same basis, namely, glycerin, and the fat is made by the chemical union of glycerin and the corresponding fatty acid. For example, the fat butyrin is made of glycerin and butyric acid. The fat stearin is made of stearic acid and glycerin. While the composition of the different butter fats are known. yet the chemist is unable to make them in the laboratory.

The fats of butter fat are divided into two main groups, the volatile and nonvolatile, and are so 
named because they are made respectively from volatile and nonvolatile fatty acids.

The fats under each class are as follows:

$\begin{array}{ll}\text { volatile } & \text { NONvolatile } \\ \text { Butyrin } & \text { Olein } \\ \text { Caprin } & \text { Myristin } \\ \text { Caproin } & \text { Palmatin } \\ \text { Caprillin } & \text { Stearin } \\ \text { Laurin } & \end{array}$

There is some dispute as to whether laurin is a volatile or nonvolatile fat, but it is usually considered volatile. The volatile fats compose about 8 per cent and the nonvolatile about, 2 per cent of butter fat. The fats of butter fat have different characteristics and properties, and one chief rlifference of fats is their melting point. For example the melting point of stearin is abunt $\mathrm{I}+3^{\circ} \mathrm{F}$., and the melting point of olein is about $40^{\circ} \mathrm{F}$ I variation in the amount of either of these $(w n$ fats would necessarily cause the melting point of butter fat to vary. The melting point of butter fat is usually between $92^{\circ} \mathrm{F}$. and $96^{\circ} \mathrm{F}$.

Casein is the chief proteid compound of milk, and forms about 20 per cent to 23 per cent of the milk solids. It exists in milk in very fine suspension, and is held in suspension by the salts of calcium. It is, therefore, sometimes called calcium casein. The casein is in such a fine state of suspension that it cannot be filtered out of the milk by any ordinary nineans. This fine state of suspension is called the colloidal state. When milk sours naturally and enough acid is found to unite with the lime salts of the milk, the casein is precipitated. Casein is alun precipitated by any acil and rennet or pepsin. Casein is valuable as food both in raw milk and in 
the products of milk, such as the various kinds of cheese. It is also used commercially in many ways, some of them being as a substitute for celluloid in the manufacture of buttons and toilet articles. It is also used in cold water paints. By a new process it is said that casein is now being made into a substitute for ivory, making excellent table tops, mantels, etc.

Sugar forms about 37 per cent to 39 per cent of the milk solids. The chief value of milk sugar is its food value in milk. It is also used in pharmacy in mixing powders, coating pills, etc. Milk sugar is not used very extensively commercially because of the expensive cost of manufacture. It is not as sweet as cane sugar, because it is not as soluble. It has the same chemical formula $\left(\mathrm{C}_{12} \mathrm{H}_{22} \mathrm{O}_{11}\right)$ as cane sugar. Acid is produced naturally in milk by the action of bacteria upon the milk sugar.

The albumen in milk is in solution. It is valuable chiefly as a food in milk. It has one commercial use in the manufacture of Italian cheese. This cheese is made where large quantities of whey are produced. The whey is heated nearly to the boiling point, and this heat precipitates the albumen. The whey is then drawn off and the albumen is dipped into molds. The cheese made from albumen forms a very good, nutritious food.

The ash is the part of milk left after burning, and it is the most constant constituent of the milk. It very rarely goes below .68 per cent or above .72 per cent. It consists chiefly of the phosphates of calcium and the chlorides of sodium, potassium, iron and magnesia.

Ash is important as a food in furnishing the mineral constituents for the body. 


\section{THE BABCOCK TEST}

The Babcock test is a test for the per cent of fat in milk and its products. It was invented by Dr. S. M. Babcock, chief chemist for the experiment station at Wisconsin, and a description of the test was published in a report of 1890 from that station. The instrument used to measure the milk is called a pipctte and holds up to its graduated mark I7.6 cc. Since milk is somewhat viscous, the pipette will deliver on an average $17.44 \mathrm{cc}$., which is for all practical purposes 18 grams. In using the pipette the milk is drawn above the $17.6 \mathrm{cc}$. mark and the soft part of the index finger placed quickly over the pipette. The column of milk can be easily controlled and allowed to flow out until it is on a level with the $17.6 \mathrm{cc}$. mark. The pipette should always be held so that the $17.6 \mathrm{cc}$. mark is on a level with the eye. The sample to be tested is measured into a special bottle with a uradiated neck, holding a column of melted fat which is a definite per cent by weight of the 18 grams of milk taken. In adding the milk to the bottle the latter should be held in a slanting position, so that the milk will run down the lower insicle of the bottle neck and will not be forced out by the outcoming air.

After measuring the milk into the bottle, 17.5 cc. of sulphuric acid $\left(\mathrm{H}_{2} \mathrm{SO}_{4}\right)$ of a specific gravity of 1.82 to 1.83 is added and the milk and acid at once thoroughly mixed. The acid burns up (by moist combustion) everything in the milk excepting the fat. The same precautions should be observed in adding the acid as in adding the milk, namely, to slant the bottle. and the bottle should be revolved as the acid is poured in, so that all of 
the milk adhering to the neck of the bottle will be washed down. The vessel containing the acid should be kept corked in order to prevent the acid taking up moisture from the air and becoming too weak for use. If the acid is too weak more than $17.5 \mathrm{cc}$. are used, and if too strong less than $17.5 \mathrm{cc}$. are used. Good acid is colorless, although it may be quite dark and at the same time be useful for the Babcock test. It must, in any case, be free from undissolved foreign particles.

After adding the acid to the milk the bottles are placed in a centrifugal machine and whirled. Care shotild be taken to have the machine balanced, $i$. e., for every bottle on one side of the machine there should be a corresponding bottle on the opposite side of the machine. The bottles are centrifugalized for five minutes and then filled with hot water up to the base of the neck. Centrifugalizing is then continued for two minutes more and hot water is added to bring the fat into the graduated neck. The centrifuge is then run for one minute.

The bottles are then ready to read, and in case of whole milk one should read between the extreme points of the fat column. This method of reading, by comparison with the chemical method, has been found to make up for the fat which remains in the bottom of the bottle and cannot be removed by centrifugalizing. The bottles should be read at a temperature of $120^{\circ} \mathrm{F}$. It is no trouble to obtain this temperature if centrifuging has been done with a steam machine. Where the machine is filled with steam the bottles should stand for from thirty seconds to one minute in a room at ordinary temperature to allow excess of heat to pass off before reading. If a hand machine is used the tester must have hot water placed in it to obtain the required 
temperature. This is especially necessary if the testing is being done in a cold room.

The machine should always be kept well oiled and securely fastened to the support on which it is being operated. Skimmed milk contains such a small amount of fat that the fat column could not be read in an ordinary whole milk bottle. A bottle is, therefore, used which has a neck with a small bore. This neck is so small that the milk and acid could not be poured through it, so a funnel tube is provided for this purpose. The skimmed milk bottle should be placed in the machine in such a position that the funnel tube will be on the outside. This will prevent fat lodging in the space between the tube and the wall of the bottle.

The sulphuric acid is added to the milk to destroy all of the milk solids except the fat, and the chief solid to be destroyed is the casein. Skimmed milk contains proportionately more casein than does whole milk and, therelore, in making a Babcock test of skimmed milk $2 \mathrm{cc}$. extra of sulphuric acid shomld be used. The fat globules in skimmed milk are small in size and correspondingly hard to remove. A Babcock sample of skimmed milk should, therefore, be whirled ten minutes, two minutes and one minute.

Cream is so viscons that it cannot be measured accurately into a test bottle by means of a pipette. It should always be weighed. The New York state dairy laws now consider it a misdemeanor to measure cream for testing where the tests are used as a basis of payment for butter fat.

Because the cream is sometimes too rich in butter fat to be tested in an ordinary cream bottle, 9 grams are tested in an 18 -gram bottle and the result multiplied by two. Nine-gram cream bottles are 
also coming into common use. These bottles give the reading direct without any computation. In testing 9 grams one would naturally use one-half the usual amount of sulphuric acid. On account, however, of the large proportion of fat present, the acid is liable to char the fat; and for this reason it is better to add approximately 9 grams of water and then add a little less than the usual amount of acid.

The fat column in the neck of a cream bottle is so large that its volume is affected by temperature. It is necessary to read the bottles at some constant temperature and the most accurate readings are obtained at temperatures from $130^{\circ} \mathrm{F}$. to $140^{\circ} \mathrm{F}$. In order to obtain the proper temperature the bottle should be allowed to stand for at least three minutes in a water bath, care being taken to have the water in the bath as high as the fat column in the bottle neck.

The meniscus on the fat column of a cream bottle is large and is not constant so that no rule for including it in the reading can be formulated. The practice is, therefore, followed of removing the meniscus by adding a few drops of glymol (white mineral oil) to the top of the fat column after the test is completed. This flattens the top of the fat column and gives the best results of any method yet devised. The glymol is easier to use if colored pink with alkana root.

Butter is tested in the cream bottles, from 3 to 4 grams being used for the test. Enough warm water is added to bring the sample up to approximately I 8 grams, and from Io to I2 $\mathrm{cc}$. of the sulphuric acid are used.

Cheese is also tested in the cream bottle, 4 to 5 grams being used. The cheese must first be minced 
with a knife as fine as possible in order to make it possible for the acid to dissolve all of the casein. After the cheese is weighed into the bottle, about $5 \mathrm{cc}$. of hot water are added and the mixture shaken vigorously for two or three minutes. This softens the casein. Enough warm water is then added to bring the sample to approximately 18 grams. The sample is again shaken for two or three minutes, and the ordinary amount of $\mathrm{H}_{2} \mathrm{SO}_{4}$ is then added. If the cheese is old and dry, 2 or 3 cc. of $\mathrm{H}_{2} \mathrm{SO}_{4}$ in excess of the usual amount are sometimes necessary to dissolve the casein. In mincing the cheese the sample should not be allowed to dry out any more than is absolutely necessary.

In the cases of both the butter and the cheese, the results obtained must be reduced to an I8-gram basis, when an 18 -gram bottle is used. This can be done by dividing the per cent obtained by the number of grams used and multiply the quotient by 18 .

Whey is ustally tested in whole milk bottles. although it is best to test it in skimmed milk bottles when possible. The right bottle to use can only be determined by actual experiment. Whey requires less acid than whole milk, usually about I2 $\mathrm{cc}$. 

EXERCISES 


\section{EXERCISE I}

\section{THE BABCOCK TEST}

I. Draw the milk above the mark on the pipette and allow the milk to settle just to the mark. Repeat this until some proficiency in the use of the pipette is obtained.

What two special precautions are to be observed in handling the pipette?

2. Test by the Babcock method a sample of whole milk. Perform this test before doing either 3 or 4 .

3. Measure out into your white cup $50 \mathrm{cc}$. of the same sample of milk used in experiment 2 . Add to this $\mathrm{I} 5 \mathrm{cc}$. of water. Mix thoroughly and test in duplicate by the Babcock method.

4. Using milk from the same sample as used in experiment 2, measure out $50 \mathrm{cc}$. of milk and add to it $5 \mathrm{cc}$. of skimmed milk. Mix thoroughly and test in duplicate by the Babcock method. The whole milk bottle should be used in experiments 3 and 4 .

Did you obtain the most fat in experiment 3 or experiment 4 ? Include in your notes a brief description of the Babcock test. 
STUDENT'S NOTES AND REPORT 


\section{EXERCISE II}

\section{BABCOCK TEST}

I. Test by the Babcock method a sample of whole milk, skimmed milk and cream.

2. $I^{\top}$ eigh into some convenient dish 18 grams of cream just tested. Add to it 20 grams of the whole milk just tested. Compute the per cent of fat in the mixture and verify your computation by testing the mixture by the Babcock method.

3. Test by the Babcock method a sample of buttermilk.

\section{STUDENT'S NOTES AND REPORT}




\section{EXERCISE III}

\section{BABCOCK TEST}

I. Test in duplicate a sample of whole milk, skimmed milk and cream. Test the skimmed milk in the same way that the whole milk is tested.

Why is cream taken by weight instead of by volume?

Why are 9 grams used instead of 18 grams?

When 9 grams of cream are tested in an I8gram bottle, what correction has to be made in the result and why?

2. Retest the cream and skimmed milk. Add acid to the skimmed milk about one-fourth of an inch above the mark on the acid measure and whirl ten minutes the first time, two minutes the second time and one minute the third time.

In retesting the cream do not add water, and use one-half the usual amount of acid.

In order to save time the cream and skimmed milk may be whirled together.

Explain fully the object of using extra acid and whirling an extra length of time in testing skimmed milk.

Record carefully any difference in the appearance of the fat column of the cream in experiments $I$ and 2.

What should be the appearance of an ideal fat column in a completed Babcock test? 
A DAIRY LABORATORY GUIDE STUDENT'S NOTES AND REPORT 


\section{EXPLANATION OF BOILED MILK TEST AND FORMALDEHYDE TEST}

There are two principal tests for boiled milk. One test makes tuse of three chemicals-hydrogen peroxide, potassium iodide and starch. In the second test two reagents are employed-hydrogen peroxide and paraphenylenediaminehydrochloride. In both cases a blue color results if the milk has not been boiled. If the milk has been boiled no blue color will result. The last named test acts more rapidly than the first one and also gives a more intense color. Any double oxide may be substituted in place of the hydrogen peroxide. Such a double oxide would be calcium peroxide. There is in milk an enzyme galactase which is destroyed by heat. When the milk has not been heated this enzyme sets free the oxygen from the oxidizing agent, and in case of the first test, the free oxygen splits up the potassium iodide and liberates free iodine. The starch in the presence of free iodine turns blue. In case of the second test the oxygen liberated by the galactase acts directly on the paraphenylenediaminehydrochloride and turns the solution blue. Hydrogen peroxide often contains sulphuric acid. When this is the case, the reagent is useless for the test with starch, as the free acid would break up the potassium iodide. If this happened a blue color would result whether the milk had been heated or not.

The test for formaldehyde is a delicate one and is easy to perform, inasmuch as it may be done in connection with the Babcock test. The regular amount of milk is measured with the $17.6 \mathrm{cc}$. pipette into a Babcock test bottle and a few drops of ferric chloride added. The regular amount of sulphuric 
acid is next added, and if formaldehyde is present a lavender-colored ring will appear between the layer of acid and the layer of milk. If the contents of the bottle are slowly mixed the dissolving casein will take on a lavender color. The test will not work if the milk is too old or if too much of the formaldehyde has been added to the milk.

Sometimes sulphuric acid contains ferric salts as an impurity; and when such is the case, the acid will give the test for formaldehyde without the use of ferric chloride. It is best however, to always add the ferric chloride to make sure there is a ferric salt present.

\section{EXPLANATION. MIXING SAMPLES OF BUTTER BEFORE TESTING FOR FAT OR MOISTURE}

Before testing a sample of butter for either moisture or fat the sample should be thoroughly nixed. Fat and water do not readily mix, and special precautions must be taken to make the sample uniform throughout. The butter should be heated and stirred until it is about the consistency of thick cream. Do not heat the butter too much, as the water and fat will entirely separate and it is difficult to remix them. The sample should then be cooled and stirred thoroughly while cooling, else the fat will cool rapidly on the outside and force all of the water towards the middle of the sample. The cooling process should be kept up until the sample is quite firm. The heating and cooling may be accomplished by placing the butter in any convenient vessel, such as a glass-stoppered sample jar. The jar may then be held under a water faucet or set in a dish of water. 


\section{EXERCISE IV}

\section{BABCOCK TEST}

I. Test by the Babcock method a sample of whole milk, skimmed milk and butter.

Mix the butter properly before weighing it out for the test.

2. Measure out about 36 grams of skimmed milk (Babcock pipette twice full to the mark). Divide approximately into four parts. Test two of these parts for boiling by two different methods. Boil the remaining 18 grams, divide approximately into two parts and test for boiling by two different methods. Give the chemicals used in each case. Do not add the chemicals to the milk while the milk is hot.

3. Measure out in duplicate a sample of skimmea milk as for the Babcock test. Before adding the sulphuric acid dip your stirring rod into the formaldehyde and rinse it off in one of the samples. Then add to both samples the ferric chloride and sulphuric acid and note the difference in color due to formaldehyde.

4. Test for formaldehyde any four of the samples furnished. Report the results by number.

Sometimes sulphuric acid will alone give the color test for formaldehyde. Why is this? Why is it best to always add the ferric chloride when making the formaldehyde test? 
STUDENT'S NOTES AND REPORT 
STUDENT'S NOTES AND REPORT 


\section{THE CORNELL BUTTER MOISTURE TEST}

When butter is heated over a flame, the casein forms a snow-white blanket over the surface of the butter. liy a comparison with the chemical method it has been found that when the bitter loses its snow-white color and turns a dirty brown color the sample has given up its moisture. When this brown color has appearerl it is time to remove the sample from the flame. Heating butter in a direct flame is liable to volatilize some of the butter, even before all of the water has been given off. In order to do away with this danger a sheet of asbestos is placed between the flame and the container of the sample. The asbestos so tempers the flame that while a high heat is produced, the danger of suddenly volatilizing the butter is largely done away with.

The scales used are made especially for use in butter-moisture work. They are so constructed that after the moisture is driven off, each notch the large weight is reversed equals I per cent of moisture clriven off, and each notch that the small weight is reversed equals. I per cent of moisture driven off. Always allow the sample to cool before weighing. While the sample is cooling it is well to cover it with something (a sheet of paper will do), so that the sample will not take water from the air. 


\section{EXERCISE V}

\section{BABCOCK TEST AND BUTTER MOISTURE}

\section{TEST}

I. Prepare a sample of butter for the moisture test and test by the Cornell method.

2. Test a sample of milk in the ordinary way.

Retest the same sample in duplicate, using only 9 grams of the sample. (It must be weighed out.) Make the sample up to 18 grams by adding water. Add the usual amount of acid.

3. Test a sample of cream in the ordinary way.

Retest the cream in the whole milk bottle, dividing 18 grams between four bottles (4 $4^{1 / 2}$ grams by weight in each bottle).

In each case add enough water to bring the sample up to 18 grams and then add the proper amount of acid as indicated by the appearance of the sample. Add the acid slowly, a little at a time, and shake thoroughly. 


\section{STUDENT'S NOTES AND REPORT}


26

A DAIRY LABORATORY GUIDE

STUDENT'S NOTES AND REPORT 


\section{THE SPECIFIC GRAVITY OF MILK AND THE LACTOMETER}

The specific gravity or density of a substance is a ratio between the weight of a given volume of the substance and the weight of a given volume of some other substance taken as a standard. The standard for liquids is water, and its specific gravity is taken as one. Milk is slightly heavier than water, and the specific gravity of normal milk averages I.032. and varies from 1.029 to 1.035 . If we add water to milk the specific gravity is lowered, because water is lighter than milk; and if we skim milk we take away fat which is lighter than milk and the specific gravity is increased. When the water is added to milk the effect is the same as it would be if the solids were actually removed from the milk. This is true because the solids which were distrihuted throughout a given volume on the addition of water, have to distribute themselves throughout the increased volume of the liquid. For this reason we say that the addition of water to milk "decreases" the total solids, and it is a fact that when water is added to milk all of the solids are decreased in the same proportion. It is important to remember this fact when one is figuring out the per cent of adulteration of milk.

The L.ictometer. - The instrument used to measure the specific gravity of a liquid is called a hydrometcr, and there are many kinds of specialized hydrometers. The hydrometer used to test the density of milk is called a lactometer, and, for the most part, only two kinds are used. One is the Qucicme (called (2) for abbreviation) and the other is called the Ordinary, or Niw York State Board of 
Health (commonly called the B. of H. lactometer). The Quevenne lactometer has a long, narrow stem which is extended into a hollow glass tube of much larger diameter than the stem itself. At the lower end of the instrument is a bulb of mercury which causes the lactometer to sink in the liquid to its proper level. The upper part of the stem contains a thermometer scale, as it is important to know the temperature of the milk when the lactometer reading is taken. This scale does not record high temperature, and, therefore, the instrument should never be placed in hot liquids. In order to clean the lactometer wash in cool water and wipe with a dry cloth. Immediately below the thermometer scale is a lactometer scale with numbers ranging from $\mathrm{I}_{5}$ to 45 , the lowest readings being at the upper end of the scale. One may obtain the specific gravity reading by prefixing 1.0 before the lactometer reading. Thus, if the instrument gives a reading of 33 , the specific gravity would be 1.033. The fact that the Quevenne lactometer gives specific gravity readings directly is one of its chief advantages.

Temperature affects the density of liquids. The colder the milk the more dense it is, and the warmer the milk the less dense it is. For this reason lactometers are standardized to give readings at a temperature of $60^{\circ} \mathrm{F}$. When milk is warmer or colder than $60^{\circ} \mathrm{F}$. a correction must be made. and this correction for the Quevenne is .I of a lactometer degree for every degree in temperature that the sample is above or below the standard temperature. When we cool the milk down we add; when we warm the milk we subtract. For example, if a lactometer gave a reading of 32 at a temperature of $66^{\circ} \mathrm{F}$., we would add $.6(. \mathrm{I} \times 6)$ to the lactometer 
reading, making the corrected or true reading 32.6 . In this case the specific gravity would be 1.0326 .

Familiarity with the action of the lactometer may be obtained by working theoretical problems, of which the following is an illustration: If the lactometer reading of a sample of milk is 31.5 at $62^{\circ} \mathrm{F}$., what would be the reading at $57^{\circ} \mathrm{F}$.? In this case $57^{\circ} \mathrm{F}$. becomes our standard, because it is the temperature to which we are going to lower the sample. Since the sample is 5 degrees too warm, $.5(.1 \times 5)$ of a lactometer degree must be added to the lactometer reading, making the true or corrected lactometer reading 32 .

When used in connection with the Babcock test the lactometer reading is important in obtaining the total solids and solids not fat of milk. There are several of these formula in use, and while they do not give quite as accurate results as the chemical method, they give results which are accurate enough for all practical purposes. They are as follows:

I. $\frac{1++.78}{3.8}=S . N . F$. Babcock's formula.

2. $\quad \stackrel{\mathrm{l}+\mathrm{r}}{4}=\mathrm{S}$. N. F. Troy's formule.

3. $1 / 4 \mathrm{~L}+.2 \mathrm{f}+. \mathrm{I} 4=\mathrm{S}$. N. F. Babcock's modified formula.

Generally speaking, the first formula gives the highest results, the second next highest and the third the lowest results. One can find the total solids by adding the fat reading to the solids not fat. In these formulæ $L$ stands for the lactometer reading and $F$ for the fat reading.

In using these formulae, the following precautions must be especially noted: Board of health readings can never be used in these formula, consequently B. of $H$. readings must be changed to $Q$.; specific gravity readings cannot be used; the per cent of fat expressed in hundredths cannot be used. 
An illustrative example will show how these formula operate. Suppose the Q. lactometer reading of a sample of milk was 32.5 at $60^{\circ} \mathrm{F}$. and the fat reading was 4.2 per cent, what are the solids not fat?

Formula $=$

I. $\frac{\mathrm{L}+.7 \mathrm{P}}{3.8}=$ S. N. F. $.7 \times 4.2=2.94$

$$
\begin{aligned}
& 2.94+32.5=35.44 \\
& 35.44 \div 3.8=9.32+
\end{aligned}
$$

Formulating the above calculation:

$\frac{32.5+2.94}{3.8}=9.32 \%$ S. N. F.

$9.32+4.2=\mathrm{I} 3.52$ total solids.

Using formula 2 :

$\frac{\mathrm{I}+\mathrm{F}}{4}=\mathrm{S}$. N. F.

$32.5+4.2=36.7$

$36.7 \div 4=9.17+\%$ S. N. F.

Formulating the above calculation:

$\frac{32.5+4.2}{4}=9.17$ S. N. F.

$9.17+4.2=13.37$ T. S.

Using formula 3 :

$\mathrm{I} / 4 \mathrm{~L}+.2 \mathrm{f}+.14=\mathrm{S} . \mathrm{N} . \mathrm{F}$.

$32.5 \div-4=8.12$

$.2 \times 4.2=.84$

$8.12+.84+.14=9$. io S. N. F.

$9.10+4.2=\mathrm{I} 3.30 \mathrm{~T} . \mathrm{S}$.

By modifying Babcock's third formula the total solids may be obtained directly. It is as follows:

$\mathrm{r} / 4 \mathrm{~L}+\mathrm{r} .2 \mathrm{f}+. \mathrm{I} 4=\mathrm{T}$. S.

Using the above lactometer and fat readings as an illustration, the formula would give the following results :

$$
\begin{aligned}
& 32.5 \div 4=8.12 \\
& 1.2 \times 4.2=5.04 \\
& 8.12+5.04+.14=\mathrm{r} 3.30 \% \text { T. S. }
\end{aligned}
$$


The following example will illustrate how a * knowledge of the per cent of S. N. F. of a sample of milk is utilized in figuring adulteration per cents:

Before adulteration a sample of milk had 4.2 per cent of fat and 9.0 per cent of S. N. F. After adulteration the sample contained 3.I per cent fat and 7.5 per cent of S. N. F. The following questions can be answered from calculations with the above data:

I. What per cent of water was added to the milk?

2. At what rate per cent was the water added?

3. What per cent of the fat was adulterated by skimming?

4. What per cent of the fat was adulterated by watering?

(I) Since there were 9 parts of S. N. F. before adulteration and 7.5 parts of S. N. F. after adulteration, I.5 must have been removed by adulteration.

$9-7.5=\mathrm{I} .5$

$1.5 \div 0=16.66 \%$ of S. N. F. removed by adding the water.

Since 16.66 per cent of S. N. F. was removed, water is the only thing that could have taken its place; therefore 16.66 per cent of water was added to the milk.

(2) For every 7.5 parts of S. N. F. in the milk I.5 parts were removed, or in other words water was added at the rate of 1.5 parts of water to every 7.5 of S. N. F.

The rate per cent at which water was added would be $1.5 \div 7.5=20 \%$.

Refore adulteration the sample had +.2 parts fat and after adulteration 3.I parts fat. I.I parts of fat were removed, which equals 26.19 per cent.

$$
\text { I. } 1 \div 4.2=26.19 \% \text {. }
$$


When milk is watered all of the solids are reduced in the same proportion. It has been found that 16.66 per cent of the S. N. F. was removed by watering; therefore, according to the above rule 16.66 per cent of the fat must have been removed by watering. But 26.19 per cent of the fat was removed; therefore the difference between 26.19 per cent and I6.66 per cent will show what is removed by skimming; $26.19-16.66=9.53 \%$ removed by skimming. 


\section{EXERCISE VI}

\section{BABCOCK TEST AND QUEVENNE LACTOMETER}

I. Test in duplicate by the Babcock method a sample of whole milk as follows:

(a) Use ordinary amount of acid.

(b) One-half usual amount of acid.

(c) Fill the bottle up to the base of the neck with acicl.

(d) Use the regular amount of acid, but warm the acid and milk before mixing until they feel warm to the hand. Add the acid slowly to the sample. Observe and record all results carefully.

Test for fat a sample of butter. Why is it arlvisable to add the acid slowly in $(d)$ question $\mathrm{I}$ ?

2. (a) Take a Quevenne lactometer reading of a sample of whole milk and skimmed milk, making corrections for temperature.

Explain fully the effect of temperature on the lactometer readings.

(b) Starting with the first reading in $2(a)$. what would have been the reading if the temperature had been $54^{\circ} \mathrm{F} .62^{\circ}$ F., $73^{\circ} \mathrm{F} ., 8 \mathrm{I}^{\circ} \mathrm{F}$.?

3. Add an acid measure full of water to the skimmed milk sample and take the Quevenne 
reading. Note any change in the lactometer reading, and explain the reasons for this change.

4. Take the Quevenne reading of a sample of skimmed milk at $60^{\circ} \mathrm{F}$.

Compute what the reading would be if the temperature were four degrees higher. Verify your results by warming the sample and taking the reading. Be sure to mix the sample thoroughly after warming it.

What is the chief advantage of the Quevenne lactometer over other kinds?

Why should the temperature of milk not be above $70^{\circ} \mathrm{F}$. or below $50^{\circ} \mathrm{F}$ when the lactometer reading is taken? 
A DAIRY LABORATORY GUIDE

STUDENT'S NOTES AND REPORT 


\section{EXPLANATION. BOARD OF HEALTH LACTOMETER}

The Board of Health lactometer (commonly called B. of $\mathrm{H}$. lactometer) is an instrument giving arbitrary readings and it must be changed to equivalent Quevenne readings in order to obtain the specific gravity. It is of the same general shape as the Quevenne, except that the thermometer scale is usually on the opposite side of the stem from the lactometer scale. The instrument is graduated from o to $\mathrm{I} 2 \mathrm{O}$, and one degree Board of Health equals .29 of one degree Quevenne. In order, therefore, to change from Board of Health to Quevenne, the Board of Health reading is multiplied by 29 . Vice versa to change from Quevenne to Board of Health reading, the Quevenne reading is divided by .29. Like the Quevenne, the Board of Health lactometer is graduated to be read at a temperature of $60^{\circ} \mathrm{F}$., and if the temperature is above or below the standard, the correction factor is 3 of one lactometer degree for every degree that the sample is above or below the standard. The following example will illustrate how correction is made: $B$. of $H$. reading IIO.5 at $65^{\circ} \mathrm{F}$., what would be the reading at $60^{\circ} \mathrm{F}$.? The sample must be cooled down 5 degrees; therefore, we would add I.5 $(5 \times .3)$ to the reading (IIO.5), making a corrected reading of II2.0. One of the chief advantages of the $\mathrm{B}$. of $\mathrm{H}$. lactometer is that a small adulteration of the milk will make a noticeable change in the lactometer reading. This is because the instrument has so large a scale. Also, when milk is watered, the number of lactometer degrees recorded below Ioo indicates roughly the per cent of adulteration. 


\section{EXPLANATION. USE OF HAND MACHINE IN BABCOCK TEST}

It is a popular notion that milk cannot be tested accurately in a hand machine. This is a mistaken idea, as a hand machine should do as good work as any other machine. One of the chief reasons for inaccuracy in using a hand machine is the inattention paid to the temperature. It is necessary to have the proper degree of heat in order to properly perform the Babcock test. To provide the proper temperature the hand machine should be filled with hot water up to the bottle cups if the room is at all cold. The small two-bottle and four-bottle hand testers have no frame, and so the bottle cups are made large in order that they may be filled with hot water if necessary. While it is not absolutely necessary to use hot water at all times, its use is always advisable. By its use the danger of testing milk at too cold a temperature is largely done away with. The operator should be careful to keep the machine to its proper speed during the entire run. 


\section{EXERCISE VII}

\section{BABCOCK TEST AND B. OF $\mathrm{H}$. LACTOMETER}

I. Take the $\mathrm{B}$. of $\mathrm{H}$. lactometer reading and make a Babcock test of a sample of whole milk. Remove the lactometer, and allow the milk to stand in your lactometer cylinder while you do No. 2. Then draw off from the top of the sample all the cream the pipette will hold. Then add to the sample I 7.6 cc. of water and mix thoroughly. Again take a lactometer reading and make a Babcock test and figure out the per cent of fat removed by skimming and the per cent of fat removed by watering; make the test in the whole milk bottles. After drawing off cream and adding water be sure to mix the sample thoroughly. Upon what rule does your ability to do the above computation depend? Better results will be obtained if the milk is warmed to about $85^{\circ}$ F. and allowed to stand as long as possible. In removing the cream keep the point of the pipette as near as possible to the surface of the liquid.

2. Test in the steam machine whole milk, skimmed milk and crean. Run the skimmed milk ten minutes, two minutes and one minute, and use acid one-quarter inch above the mark on the acid measure. Retest the whole milk in the hand machine and compare the results with those obtained in the steam machine.

3. (a) Take the $\mathrm{B}$. of $\mathrm{H}$. lactometer reading of a sample of skimmed milk. See how much water it will take to lower the lactometer reading one clesree. Great care must be taken to mix the water with the milk as the former is poured in. This is 
best done by pouring the milk from one vessel to another.

(b) See if one gram of salt will bring the reading back to where it was originally. 


\section{EXPLANATION. ACIDITY OF MILK}

The acidity of milk is of two kinds-apparent and ral acidity. The apparent acidity is due to the acid reaction of the acid phosphates and casein. The real acidity is due to the presence of lactic acid $\left(\mathrm{C}_{3,} \mathrm{I}_{6} \mathrm{O}_{33}\right)$, which is produced by the action of bacteria upon the sugar of the milk. The following reaction is supposed to be the one which takes place:

$$
\mathrm{C}_{12} \mathrm{H}_{22} \mathrm{O}_{11}+\mathrm{H}_{2} \mathrm{O}={ }_{4} \mathrm{C}_{3} \mathrm{H}_{6} \mathrm{O}_{3}
$$

The apparent acirlity, according to Van Slyke, does not go above .08 per cent to.I per cent, and is of minor importance so far as dairy work is concerned. In determining the acidity of milk it is assumed that all of the acidity is due to the presence of lactic acid.

The real acidity will ordinarily go as high as I per cent, and in some cases, higher. Usually, however, when from 8 per cent to I per cent acidity is reached the lactic acid organisms will cease working. If a part of the acid is neutralized the organisms will again commence the production of acid.

Lactic acid is important in the manufacture of dairy products. For example, butter is churned from cream which is soured or "ripened "by lactic acill. The presence and amount of lactic acid is very important all through the process of cheese making. In many cases the nature of the product depends on the amount of acid present during the successive steps of manufacture.

For thesc reasons it is necessary to have some means of finding the amount of acid in the milk. The process by which this is done is called titration. 
It is a principle of chemistry that an alkali will neutralize an acid. In order, therefore, to find the acid in the milk we take a known quantity of the milk and measure into it an alkali whose strength we know. The instrument used to measure the amount of alkali used is called a burette, and the unit of measure is the cubic centimeter. It is commonly graduated as fine as tenths of a cubic centimeter. One can tell when all of the acid is neutralized by means of an indicator. The indicator used most in dairy work is phenolphthalein, which is colorless in acid and pink in alkali. If two or three drops of the indicator are put in milk the color will not change, because the milk is acid in reaction. The instant that just enough alkali is added to the milk to neutralize all of the acid the solution will turn pink.

It is a chemical fact that equal volumes of acids and alkalies of the same chemical strength will exactly neutralize one another. In I cc. of a normal solution of lactic acid there are .09 grams of lactic acid. According to the above rule I cc. of any normal alkali solution would just neutralize .o9 grams of lactic acid.

In actual practice a solution weaker than a normal solution is usually employed, because a normal solution is so strong that any small variation in the amount used makes a big variation in results. A common solution used is $I / I O$ normal (expressed $\mathrm{n} / \mathrm{Io}$ ). One cc. of an $\mathrm{n} / \mathrm{Io}$ alkali solution would neutralize 009 grams of lactic acid. An example will illustrate how the per cent of acid in milk is calculated. Suppose it took $6 \mathrm{cc}$. of $\mathrm{n} /$ Io alkali solution to neutralize the acid in 20 grams of milk. What is the per cent of acid? One cc. of $n /$ Io alkali will neutralize .009 grams of lactic acid. Six cc. will 
neutralize $6 \times .009=.054$ grams of acid. $.054 \div 20=$ $.0027 .0027 \times 100=.27 \%$ acid in the milk. Formulated, the above example is expressed as follows:

$$
\frac{.009 \times 6}{20} \times 100=.27 \%
$$

If the milk for the acid test is measured in cubic centimeters it should be reduced to grams by multiplying by the specific gravity of milk. The acid is obtained in terms of grams and we cannot divide grams by cc. and obtain per cent.

Professor Farrington has devised some alkali tablets, each one of which will neutralize .03492 grams of lactic acid. These tablets are dissolved in water and an alkali solution made. The strength of the solution per cc. will vary according to the number of tablets used and the number of $\mathrm{cc}$. of water in which they are dissolved. The indicator is added to the tablets when they are manufactured. Consequently, when using an alkali tablet solution no phenolphtholein is needed. A concrete example will show how these tablets are used.

Suppose that it required $\mathrm{I} 5 \mathrm{cc}$. of an alkali tablet solution to neutralize the acid in 20 grams of milk. The tablet solution was made by dissolving five tablets in $100 \mathrm{cc}$. of water. What is the per cent of acid in the milk?

$.03492=$ grams of lactic acid one tablet will neutralize. $.03492 \times 5=.1746$ grams of lactic acid five tablets will neutralize. Since the five tablets are dissolved in $100 \mathrm{cc}$. of water . 1746 is the amount of lactic acid IOO $\mathrm{cc}$. of the solution will neutralize. Then $.1746 \div 100=.001746$, the strength of $\mathrm{I} \mathrm{cc}$. of the solution: in other words, the number of grams of lactic acid I cc. of the solution will neutralize.

$.001746 \times 15=.026190$

$.026190 \div 20=.0013095 \times 100=.13095 \%$ 
If five of the alkali tablets are dissolved in $97 \mathrm{cc}$. of water each cubic centimeter of the solution will neutralize . OI per cent of acid when I8 grams of milk are used. This solution is often used by creamerymen, as the per cent of acid may then be read directly from the burette. Many devices for testing the acidity of milk are on the market, all tending to do away with computation and giving the percentage of acid directly. One of these is Publow's acidimeter. In this apparatus an $\mathrm{n} /$ Io alkali solution is used and 9 grams of milk are tested. Each cc. on the burette equals .I per cent of acid and each I/ro of a cc. equals . OI per cent acid. In testing for acid one should always try and obtain the same degree of color each time. This color should be permanent for at least one minute. Great care should be taken not to run in an excess of alkali. It will be much easier to detect the color change if some water is added to the sample after it is measured out before the alkali is added. 


\section{EXERCISE VIII}

\section{BABCOCK TEST AND ACID TEST}

I. (a) Test by the Babcock method, butter, cream and whole milk. Compute the weight of the fat column in the cream test.

(b) Retest the whole milk, putting 9 grams in one bottle and 5 grams in the other. Reduce each reading to a basis of 18 grams.

2. (a) Test the skimmed milk for per cent of acid, using $\mathrm{n} / \mathrm{ro}$ alkali solution, and using $17.6 \mathrm{cc}$. of milk. Do not add water to the sample.

(b) Retest the skimmed milk, using $25 \mathrm{cc}$. of milk and compare with first test.

(c) Measure out I8 grams of skimmed milk and add to this $17.6 \mathrm{cc}$. of water. Test for acid and compare with the first test.

(d) Measure out $20 \mathrm{cc}$. of skimmed milk from same sample as used in above experiments and add to it 3 cc. of buttermilk or starter and test for acid. What is the object of using different amounts in (a) and (b)? What is the object of adding water to $(c)$ ?

3. Take the $B$. of $H$. lactometer reading of the whole milk and compute per cent of T.S. and $S$. N. F.

4. Take a B. of $H$. lactometer reading of skimmed milk. Cool the milk as low as possible and compute what the reading would be at this temperature. Then compare your computation with the actual reading. 
Perform the same experiment, heating the milk to $95^{\circ} \mathrm{F}$. The object of this experiment is to show the incorrectness of a correction factor when used at a temperature of more than $10^{\circ} \mathrm{F}$, either above or below $60^{\circ} \mathrm{F}$. 
A DAIRY LABORATORY GUIDE

\section{STUDENT'S NOTES AND REPORT}




\section{EXPLANATION. EFFECT OF SPEED OF MACHINE ON BABCOCK TEST}

The following exercise illustrates the influence of the speed of the machine on the amount of fat brought to the surface. The speed of the machine is important, because the greater the speed the more force exerted. One should always run a Babcock tester up to the speed indicated in the directions for running the machine. Sometimes one will make as good a test when running a machine slow as when running faster. This, however, is not always the case, and in operating the tester one must be sure that the machine is run fast enough to bring all of the fat into the neck of the bottle. 


\section{EXERCISE IX}

\section{BABCOCK TEST AND LACTOMETER}

I. (a) Test by the Babcock method a sample of whole milk and skimmed milk.

(b) Test the butter in the hand machine.

(c) Retest the whole milk in the steam machine, but do not let the speed of the machine exceed 250 revolutions per minute.

In performing the above experiment it is best to experiment with the machine before putting in your samples. Otherwise, you will be liable to run the machine too fast.

2. (a) Take a lactometer reading of the whole milk and figure out the S. N. F. and T.S.

(b) Take a lactometer reading of the skimmed milk and figure out the S. N. F. and T.S.

3. (a) Test the skimmed milk for acid with $\mathrm{n} /$ io alkali solution and the alkali tablet solution. The alkali tablet solution was made by dissolving eight tablets in $95 \mathrm{cc}$. of water.

(b) Test for acid I 8 grams of tap water. Add to 18 grams of tap water $3 \mathrm{cc}$. of starter or buttermilk, again test for acid. Use n/Io alkali solution. 
A DAIRY LABORATORY GUIDE

\section{STUDENT'S NOTES AND REPORT}




\section{EXERCISE $X$}

\section{BABCOCK TEST. LACTOMETER READING AND ACID TEST}

I. Make a Babcock test of cheese, whole milk and skimmed milk. Add acid to the skimmed milk about one-quarter of an inch above the usual mark, and run ten minutes, two minutes and one minute.

Run the whole milk the usual time at the usual speed. Be sure to cut the cheese fine before putting into the test bottle.

2. (a) Retest the whole milk, running the machine one minute, one minute, one minute. $\mathrm{Bc}$ careful to run the machine at the same speed at which it was run the first time. Do you get any different results either in the amount or the appearance of fat? If so, give the reasons.

(b) Retest the whole milk, running the machine fifteen minutes, five minutes and three minutes. Do you get any more fat than when the machine is run the usual length of time? Be careful to run the machine at the same speed at which it was run the first time.

Oil the machine well before each run.

3. Take the B. of $\mathrm{H}$. lactometer reading of skimmed milk and whole milk. Make corrections for temperature and figure out the $S . N$. F. and T. S. for whole milk, using three formulæ. 
4. Test the whole milk for acid, using I8 grams.

Use both $\mathrm{n} / \mathrm{IO}$ and alkali tablet solution. Test the skimmed milk for acid, with the n/Io solution. Use only $5 \mathrm{cc}$. of the milk. Do this twice, so that one result will be a check on the other. Again test the skimmed milk, using a 50-cc. sample. Do this twice. See if you get the more uniform results with the large sample.

\section{STUDENT'S NOTES AND REPORT}


$\Lambda$ DAIRY LABORATORY GUIDE

\section{STUDENT'S NOTES AND REPORT}




\section{EXPLANATION OF EXERCISE XI}

In testing butter by the Babcock method, the practice is sometimes followed of melting the butter and then putting it into the test bottle by means of the pipette. It is posssible to do this sometimes and get accurate results, but the tendency for fat and water to separate makes it difficult to get accurate tests.

Division $b$ of experiment 2 illustrates how readily the fat and water separate. In drawing off the fat for this experiment, keep the point of the pipette at the surface of the fat.

Carbon dioxide acts toward an alkali like an acid. We are told that some of the acidity of the milk is due to the presence of $\mathrm{CO}_{2}$. In experiment 4 , pouring the milk back and forth from one vessel to another tends to mix the $\mathrm{CO}_{2}$ of the air with the milk. Heat will expel the $\mathrm{CO}_{2}$, and so after boiling the milk the acid test would be lower than it would be before boiling. This experiment also shows that milk will take up gases.

In the same way that acids and alkalies form reactions so do solutions of certain salts form reactions. When salts do react they follow the same rule as acids and alkalies, namely, that equal volumes of salts of the same chemical strength will just neutralize one another. This fact is made use of in determining, quantitatively, the amount of salt (sodium chloride) in butter. The salt used to neutralize the sodium chloride is silver nitrate ( $\mathrm{Ag}$ $\mathrm{No}_{3}$ ) and the indicator used to tell when enough silver nitrate has been added is a solu- 
tion of potassium chromate $\left(\mathrm{K}_{2} \mathrm{Cr} \mathrm{O}_{4}\right)$. This indicator added to sodium chloride solution produces a lemon yellow color. When enough silver nitrate has been added to just neutralize all of the sodium chloride the solution turns a light brown color. No more silver nitrate should be added when a permanent light brown color is obtained.

The chemical reaction which takes place is as follows:

$$
\mathrm{Nacl}+\mathrm{Ag} \mathrm{No} \mathrm{No}_{3}=\mathrm{Na} \mathrm{No}_{3}+\mathrm{Agcl}
$$

One cc. of $n /$ Io silver nitrate solution will neutralize .00585 grams of sodium chloride. Since the butter is in solid form, it is necessary to dissolve the sodium chloride and this is done by washing the butter in a definite amount of warm water, and titrating the water.

Suppose Io grams of butter are washed in 200 cc. of warm water and it takes $6 \mathrm{cc}$. of silver nitrate solution to neutralize the salt in $50 \mathrm{cc}$. of the wash water. It would then require 24 cc. of silver nitrate solution to neutralize the salt in $200 \mathrm{cc}$. of wash water. Since I cc. of silver nitrate will neutralize .00585 grams of salt (sodium chloride) $24 \mathrm{cc}$. will neutralize .I 404 grams of salt $(24 \times .00585=$. I 404$)$.

This salt was obtained from Io grams of butter so .I 404 grams of salt divided by Io grams of butter, and the quotient multiplied by IOO will give 1.404 the per cent of salt in the butter. 


\section{EXERCISE XI}

\section{BABCOCK TEST AND ACID TEST}

I. Make up an alkali tablet solution as directed. Shake frequently, and set aside for use later in the exercise.

2. (a) Test by the Babcock method a sample of whole milk and a sample of butter.

(b) Place a piece of butter in your acid measure and allow it to stand in a cup of hot water for about fifteen minutes. Then with a pipette draw the fat from the surface of the liquid. Weigh out the proper amount and test by the Babcock method. What conclusions do you draw from this experiment?

3. Test for acid a sample of starter, using the alkali tablet solution furnished and $\mathrm{n}$ / $\mathrm{ro}$ alkali solution. Use $3 \mathrm{cc}$. of starter.

4. Pour back and forth from one vessel to another about Ioo cc. of skimmed milk. Do this for about three minutes. Test $25 \mathrm{cc}$. of it for acid, using the alkali tablet solution which you made up at the beginning of the exercise. Then boil about $35 \mathrm{cc}$. of the milk for about one minute; cool; keep covered while cooling, and retest $25 \mathrm{cc}$. for acid. Compare with first test and see if you get lower results.

Explain fully why lower results may be expected with boiled milk.

The alkali tablet solution was made by dissolving ro alkali tablets in II $5 \mathrm{cc}$. of water. 
A DAIRY LABORATORY GUIDE

61 STUDENT'S NOTES AND REPORT 
62

A DAIRY LABORATORY GUIDE

STUDENT'S NOTES AND REPORT 


\section{EXERCISE XII}

\section{BABCOCK TEST AND BUTTER MOISTURE TEST}

I. Test a sample of cheese, whole milk and skimmed milk for butter fat. In testing cheese, weigh out $4 \frac{1}{2}$ grams of the material and use the cream bottle. In testing the skimmed milk, run extra time and use extra acid as previously directed.

2. Test cheese for acid, using $n /$ Io alkali solution.

In order to test cheese for acid, weigh out 3 grams. Place in a white cup and add $17.6 \mathrm{cc}$. of warm water. Then with a stirring rod grind the cheese up as fine as possible. This will take at least five minutes. Then test the solution as usual, and calculate the per cent of acid in terms of lactic acid.

3. Test a sample of butter for moisture by the Cornell method.

4. Test for salt a sample of butter, using an $n / 10$ silver nitrate solution. Use Io grams of butter and $250 \mathrm{cc}$. of water. Titrate at least three $50 \mathrm{cc}$. portions of water and check results carefully.

Note.-To what is the high acid content of cheese due? 
54

A DAIRY LABORATORY GUIDE

STUDENT'S NOTES AND REPORT 
A DAIRY LABORATORY GUIDE

\section{STUDENT'S NOTES AND REPORT}


A DAIRY LABORATORY GUIDE

\section{STUDENT'S NOTES AND REPORT}




\section{STUDENT'S NOTES AND REPORT}




\section{EXERCISE XIII}

\section{BABCOCK TEST, LACTOMETER AND ACID TEST}

I. Test by the Babcock method a sample of whole milk, cottage cheese and buttermilk. Fill your lightning top sample jar about one-third full of whole milk, add a preservative tablet and shake at intervals until tablet is dissolved. Set the sample away in your desk and test at the next exercise.

Use 9 grams of cottage cheese, and add 9 grams of water. Test in whole milk bottle. Shake well after adding acid.

2. To about 54 grams of skimmed milk add $2 \mathrm{cc}$. of light machine oil, shake thoroughly. Using the whole milk test bottle, test the sample in duplicate by the Babcock method. Compare the appearance of the fat column with that obtained with ordinary butter.

3. Test with the alkali tablet solution the acid in the whole milk and buttermilk.

4. Take a lactometer reading of the whole milk. Add some water (about $25 \mathrm{cc}$.) to the sample. Again take a lactometer reading and make a Babcock test. Figure out T. S. and S. N. F. and the per cent of the water added.

5. Test for salt a sample of butter using Io grams of butter and $300 \mathrm{cc}$. of water. Titrate several $17.5 \mathrm{cc}$. portions of the water and check results carefully. 
A DAIRY LABORATORY GUIDE

STUDENT'S NOTES AND REPORT 
68

A DAIRY IABORATORY GUIDE

STUDENT'S NOTES AND REPORT 


\section{EXPLANATION. COMMERCIAL RENNET AND ITS USE}

Commercial rennet is a liquid prepared by soaking in brine the fourth stomach of the calf. It has under certain conditions the power of precipitating the casein from milk. It is so desirable for this purpose that rennet is used almost exclusively in the manufacture of cheese. One peculiar characteristic of rennet is the fact that it is not destroyed by its use in precipitating casein. If it could be extracted the same rennet could be used over and over again for precipitating the casein in different lots of milk.

Temperature has a decided effect upon the action of rennet. The colder milk is, the less rapid the rennet action. This is very noticeable at temperatures below $80^{\circ} \mathrm{F}$. The rennet acts most rapidly at temperatures from $100^{\circ} \mathrm{F}$. to $120^{\circ} \mathrm{F}$. At $130^{\circ}$ $F$. the action of the rennet is less active and its action is entirely destroyed somewhere between $140^{\circ} \mathrm{F}$. and $150^{\circ} \mathrm{F}$. The high temperature destroys the rennin, which is the active principle of the rennet. The action of rennet increases as the acid in the milk increases. The action of rennet seems to depend to a great degree upon the solubility of the lime salts of the milk. If an insoluble lime salt is added to the milk, the action of the rennet is retarded, and if a soluble lime salt is added to milk the action of rennet is hastened. If milk is heated to a high temperature the lime salts are supposed to be rendered insoluble and the rennet has no effect on the casein. Freezing does not seem to injure rennet. When it is again melted and given the proper temperature it will act as though it had never been frozen. 


\section{EXERCISE XIV}

\section{BABCOCK TEST, MICROSCOPIC APPEAR- ANCE OF MILK, USE OF RENNET}

I. Test the sample preserved at the last exercise.

2. Examine under the high-power tuicroscope cream, whole milk and skimmed milk. Make a drawing of each field. Describe fully the difference in the appearance of the fat globules in each of the three fields.

3. Heat 18 grams of skimmed milk to about $100^{\circ}$ F. and add four drops of rennet; shake thoroughly and let stand. Note the length of time it takes the milk to curdle.

4. To one-half a teacup of water add six drops of sulphuric acid. Add three drops of this solution to 18 grams of milk. Heat to about $100^{\circ}$ $\mathrm{F}$. and note the time it takes for milk to coagulate. Compare length of time with that required in No. 3.

5. To about 20 grams of skimmed milk add six drops of sulphuric acid and shake thoroughly. Note time it takes the milk to coagulate and compare the coagulum with that obtained when rennet is used.

6. Measure out two $25 \mathrm{cc}$. samples of skimmed milk. Warm to $80^{\circ} \mathrm{F}$. To one sample add five drops of rennet; to the other add five drops of sulphuric acid. Note and compare the length of time it takes each to coagulate. What two things hasten the action of rennet in milk? 
A DAIRY LABORATORY GUIDE

STUDENT'S NOTES AND REPORT 
74

A DAIRY LABORATORY GUIDE

STUDENT'S NOTES AND REPORT 
STUDENT'S NOTES AND REPORT 


\section{EXERCISE XVI}

\section{BABCOCK TEST AND LACTOMETER READING}

I. Take a lactometer reading and make a Babcock test of a sample of whole milk. Compute the T. S. and the S. N. F. Allow the sample to stand in the lactometer cylinder while you do No. 2. Then remove all of the cream possible and add $25 \mathrm{cc}$. of water. Again make a Babcock test, and take a lactometer reading. Compute the per cent of water added, the rate per cent at which water was added, the per cent of fat removed by skimming. the per cent of fat removed by watering and the rate per cent at which the fat was removed.

2. Test in the steam machine a sample of whole milk, and a sample of butter. Retest a sample from the same lot of milk in the hand machine and fill the machine with water at $60^{\circ} \mathrm{F}$. Note the result of the low temperature upon the fat column. Run the same bottles which were tested in the hand machine in the steam machine for a period of three minutes and then read the fat column. Note if there is any increase in the fat column. 
A DAIRY LABORATORY GUIDE

77

STUDENT'S NOTES AND REPORT 


\section{EXERCISE XVII}

\section{USE OF RENNET. PRECIPITATION OF ALBUMEN}

I. Take 18 grams of milk in a white cup and cool to $50^{\circ} \mathrm{F}$. Add four drops of rennet and note time it takes the milk to coagulate. Compare this with the same amount of milk warmed to $85^{\circ} \mathrm{F}$., to which four drops of rennet have been added.

2. Boil some whey and note the albumen which is thrown down in a white flocculent precipitate. Fill your lightning top sample jar about one-half full of skimmed milk at about $100^{\circ} \mathrm{F}$. Add I cc. of rennet. Set aside to coagulate. Then strain off the whey and precipitate the albumen in the whey by boiling.

In both cases the boiling should be done in a test tube. It may at first be difficult to see albumen, as it is in very fine particles. The albumen may be distinguished more readily by holding the test tube between the eye and the window.

Turn in desk, key and locker. See that all glassware is clean before turning in the desk. 
80

A DAIRY LABORATORY GUIDE

STUDENT'S NOTES AND REPORT 


\section{STUDENT'S NOTES AND REPORT}





\section{INDEX}

Acid :

PAGE

Lactic ............................... 43

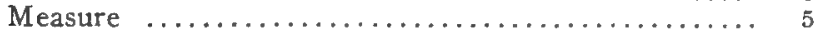

In Milk ............................... 43

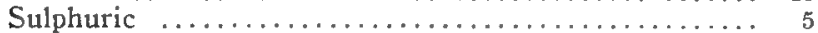

Acidity :

Apparent and real........................ 43

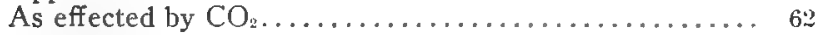

Alkali Tablet Solution........................... 45

Babcock Test .............................. 5

Boiled Milk Test............................ 18

Burette ................................... 44

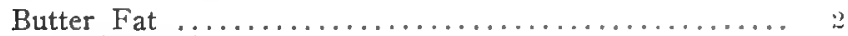

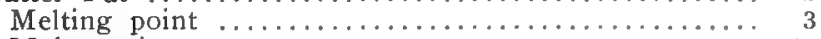

Moisture in .............................. 19

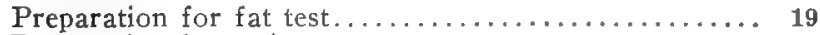

Preparation for moisture test. ................. 23

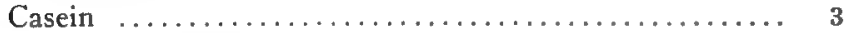

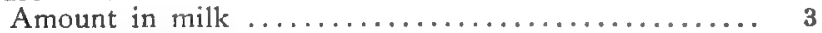

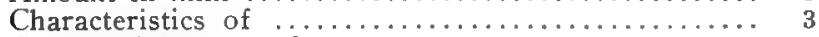

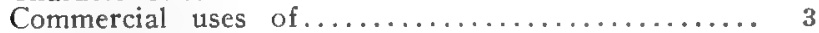

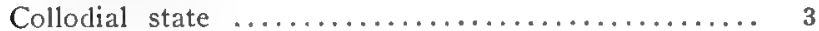

Cornell Moisture Test........................ 23

Cream $\ldots \ldots \ldots \ldots \ldots \ldots \ldots \ldots \ldots \ldots \ldots \ldots \ldots \ldots \ldots \ldots \ldots$

$V_{\text {iscosity of } \ldots \ldots \ldots \ldots \ldots \ldots \ldots \ldots \ldots \ldots \ldots \ldots \ldots \ldots \ldots \ldots \ldots \ldots \ldots}$

Weighing for testing...................... 7

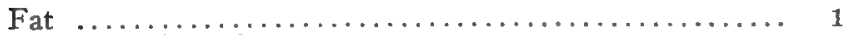

Composition of .......................... 3

Formaldehyde Test ........................ 18

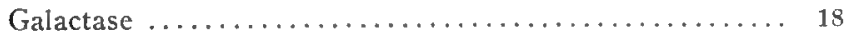

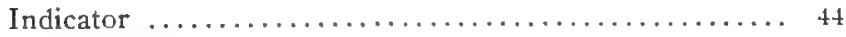

Lactometer ............................. 27

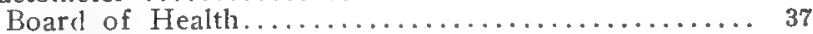

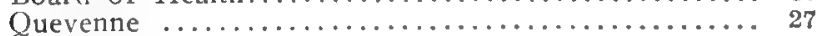

Uses of ............................... 29

Machines ............................. 6

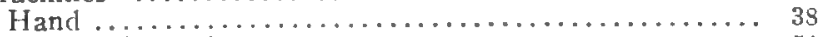

Effect of speed on test..................... 51

Melting Point of Butter Fat.................. 3 
Milk PAGE

Adulteration ................................... 31

Albumen in .............................. 4

Ash in ................................... 4

Composition of ............................. 1

Casein in ................................. 3

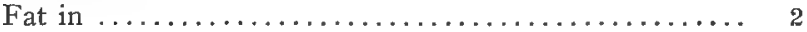

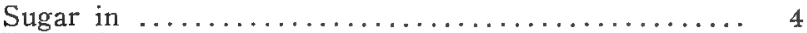

Water in ................................ 1

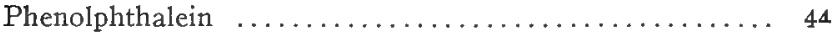

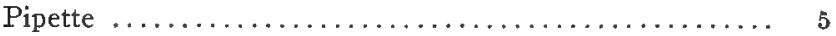

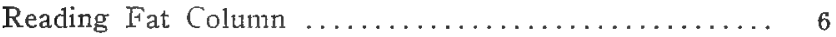

Rennet .............................. 69

Effect of acid on action $\ldots \ldots \ldots \ldots \ldots \ldots \ldots \ldots 96$

Effect of temperature on action ............ 69

Salt, test for ........................ 59

Solids Not Fat........................... 29

Formulæ for finding...................... 29

Specific Gravity .......................... 27

Of milk ............................ 27

Testing:

Butter .............................. 8

Cheese ................................. 8

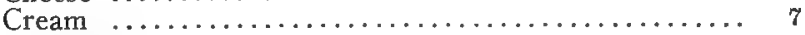

Skimmed milk ........................... 7

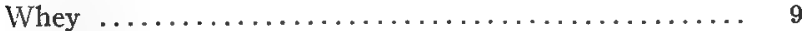

Whole milk ............................... 5

Temperature :

Effect on lactometer reading................. 28

Effect on fat column......................... 6

Effect on rennet action..................... 69 


\section{STANDARD BOOKS}

PUBRISHED BY

\section{ORANGE JUDD COMPANY}

NEW YORK

Ashland Building

\author{
CHICAGO
}

People's Gas Building

150 Michigan Avenue

Any of thesr books will be sent by mail, postpaid, to any part of the world, on receipt of catalog price. We are always happy to correspond with our patrons, and cordially invite them to address us on any matter pertaining to rural books. Send for our large illustrated catalog, free on application.

\section{First Principles of Soil Fertility}

By Alfred Vivian. There is no subject of more vital importance to the farmer than that of the best method of maintaining the fertility of the sotl. The very evident decrease in the fertility of those soils which have been under cultivation for a number of years, combined with the increased competition and the advanced price of labor, have convinced the intelligent farmer that the agriculture of the future must be based upon more rational practices than those which have been followed in the past. We have felt for some time that there was a place for a brief, and at the same time comprehensive, treatise on this important subject of Soil Fertility. Professor Vivian's experience as a teacher in the short winter courses has admirably fitted him to present this matter in a popular style. In this little book he has given the gist of the subject in plain language, practically devoid of technical and scientific terms. It is pre-eminently a "First Book," and will be found especially valuable to those who desire an introduction to the subject, and who intend to do subsequent reading. Illustrated. $5 \times 7$ inches. 265 pages. Cloth.

\section{The Study of Corn}

By Prof. V. M. Shoesmith. A m ust helpful book to all farmers and students interested in the selection and improvement of corn. It is profusely illustrated from photographs, all of which carry their own story an' contribute their part in making pictures and text matter a clear, concise and interesting study of corn. Illustrated. $5 \times 7$ inches. roo pages. Cloth. ........ Net, $\$ 0.50$ 


\section{The Cereals in America}

By Thomas F. Hunt, M.S., D.Agri. Professor of Agronomy, Cornell University. If you raise tive acres of any kind of grain you cannot afford to be without this book. It is in every way the best book on the subject that has ever been written. It treats of the cultivation and improvement of every grain crop raised in America in a thoroughly practical and accurate manner. The subject-matter includes a comprehensive and succinct treatise of wheat, maize, oats, barley, rye, rice, sorghum (kafir corn) and buckwheat, as related particularly to American conditions. First-hand knowledge has been the policy of the author in his work, and every crop treated is presented in the light of individual study of the plant. If you have this book you have the latest and best that has been written upon the subject. Illustrated. 450 pages. $5 \frac{1}{2} \times 8$ inches. Cloth.

\section{The Forage and Fiber Crops in America}

By Thomas F. Hunt. This book is exactly what its title indicates. It is indispensable to the farmer, student and teacher who wishes all the latest and most important information on the subject of forage and fiber crops. Like its famous companion, "The Cereals in America," by the same author, it treats of the cultivation and improvement of every one of the forage and fiber crops. With this book in hand, you have the latest and most up-to-date information available. Illustrated. 428 pages. 5 I $/ 2 \times 8$ inches. Cloth. . . . \$I.75

\section{The Book of Alfalfa}

History, Cultivation and Merits. Its Uses as a Forage and Fertilizer. The appearance of the Hon. F. D. CoBurN's little book on Alfalfa a few years ago has been a profit revelation to thousands of farmers throughout the country, and the increasing demand for still more information on the subject has induced the author to prepare the present volume, which is by far the most authoritative, complete and valuable work on this forage crop published anywhere. It is printed on fine paper and illustrated with many full-page photographs that were taken with the especial view of their relation to the text. 336 pages. $6^{\mathrm{t} / 2} \times 9$ inches. Bound in cloth, with gold stamping. It is unquestionably the handsomest agricultural reference book that has ever been issued. Price, postpaid, . $\$ 2 . \infty$

\section{Clean Milk}

By S. D. Belcher, M.D. In this book the author sets forth practical methods for the exclusion of bacteria from milk, and how to prevent contamination of milk from the stable to the consumer. Illustrated. $5 \times 7$ inches. I46 pages. Cloth. . . . . . . . . \$I OO 


\section{Feeding Farm Animals}

By Professor Thomas Shaw. This book is inteuded alle.for the student and the farmer. The author has succeeded in giving in regular and orderly sequence, and in language so simple that a child can understand it, the principles that govern the science and practice of feeding farm animals. Professor Shaw is certainly to be congratulated on the successful manner in which he has accomplished a most difficult task. His book is unquestionably the most practical work which has appeared on the subject of feeding farm animals. Illustrated. $5 \frac{1}{2} \times 8$ inches. Upward of 500 pages. Cloth. . . . \$2.00

\section{Profitable Dairying}

By C. L. Peck. A practical guide to successful dairy management. The treatment of the entire subject is thoroughly practical, being principally a description of the methods practiced by the author. A specially valuable part of this book consists of a minute description of the far-famed model dairy farm of Rev. J. D. Detrich, near Philadelphia, Pa. On the farm of fifteen acres, which twenty years ago could not maintain one horse and two cows, there are now kept twenty-seven dairy cattle, in addition to two horses. All the roughage, iitter, bedding, etc., necessary for these animals are grown on these fifteen acres, more than most farmers could accomplish on one hundred acres. Illustrated. $5 \times 7$ inches. 200 pages. Cloth.

. $\$ 0.75$

\section{Practical Dairy Bacteriology}

By Dr. H. W. Conn, of Wesleyan University. A complete exposition of important facts concerning the relation of bacteria to various problems related to milk. A book for the classroom, laboratory, factory and farm. Equally useful to the teacher, student, factory man and practical dairyman. Fully illustrated with 83 original pictures. 340 pages. Cloth. $5 \frac{1}{2} \times 8$ inches.

\section{Modern Methods of Testing Milk and Milk Products}

By L. L. VanSlyke. This is a clear and concise discussion. of the approved methods of testing milk and milk products. All the questions involved in the various methods of testing milk and cream are handled with rare skill and yet in so plain a manner that they can be fully understood by all. The book should be in the hands of every dairyman, teacher or student. Illustrated. 214 pages. $5 \times 7$ inches. . . . . Net, \$1.W 


D. 